\title{
Instructions aux auteurs
}

Les Annales HSS n'acceptent que les travaux originaux et inédits. Tout manuscrit proposé est soumis au comité de la rédaction dans un délai de six mois et fait l'objet d'une évaluation par deux experts extérieurs. La nationalité des auteurs ainsi que leur appartenance institutionnelle doivent être précisées.

Les manuscrits doivent être envoyés à l'adresse annales@ehess.fr dans un format de type Word ou Open Office. Cartes ou graphiques sont remis dans des fichiers séparés, en format natif, PDF ou EPS. Ils sont accompagnés de titres, de légendes et de la mention des sources.

Le texte doit être présenté en double interligne et suivre nos recommandations disponibles à l'adresse http://annales.ehess.fr/index.php?210. Il ne doit pas dépasser les 90000 signes (notes et espaces compris), les notes en bas de page seront limitées à 100. Les citations en langue étrangère seront traduites, l'original donné éventuellement en note.

Tout manuscrit doit être accompagné d'un résumé en français et en anglais (précédé de son titre traduit) d'environ 1500 signes.

Nous attirons l'attention des auteurs sur le fait que leur article, une fois accepté pour publication, sera traduit en anglais pour diffusion en ligne. Les auteurs seront mis en contact direct avec les traducteurs, ce dialogue favorisant la réalisation d'une traduction scientifique de qualité.

Les auteurs sont informés qu'il leur revient de trouver, au préalable, les versions originales anglaises des citations qu'ils fournissent en français dans leur article, lorsqu'il en existe une édition canonique. Ils s'engagent à fournir un fichier de ces versions anglaises, contenant aussi les nouvelles références éditoriales, les versions anglophones des noms propres cités, ainsi que celles des concepts employés, fichier transmis au traducteur le moment venu. 


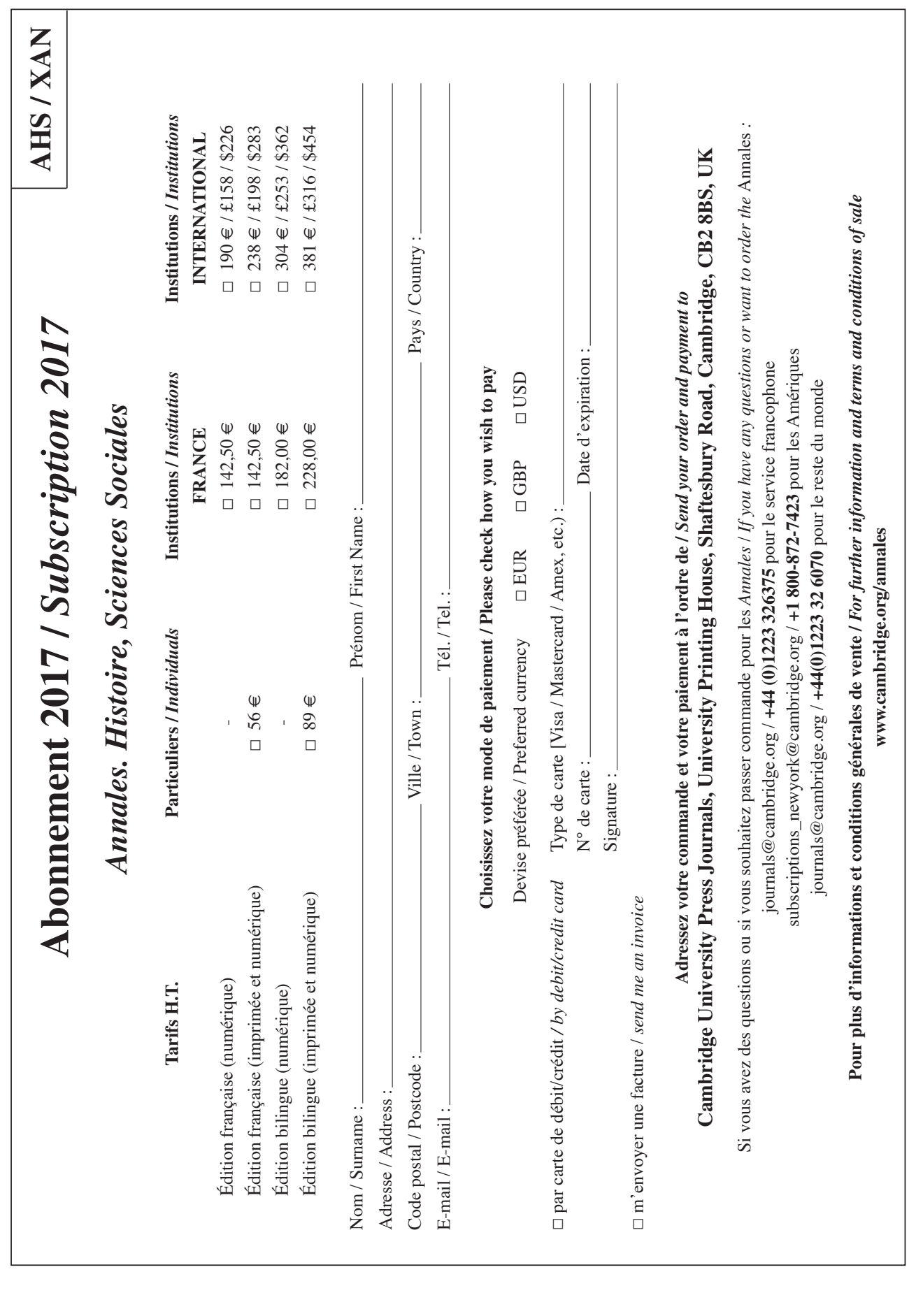


Tous droits de traduction, d'adaptation et de reproduction par tous procédés, réservés pour tous pays.

Le Code de la propriété intellectuelle n'autorisant, aux termes de l'article L. $122-5,2^{\circ}$ et $3^{\circ} \mathrm{a}$, d'une part que les « copies ou reproductions strictement réservées à l'usage privé du copiste et non destinées à une utilisation collective» et, d'autre part, que les analyses et les courtes citations dans un but d'exemple et d'illustration, «toute représentation ou reproduction intégrale ou partielle faite sans le consentement de l'auteur ou de ses ayants droit ou ayants cause est illicite» (art. L. 122-4 du CPI). Cette représentation ou reproduction, par quelque procédé que ce soit, constituerait donc une contrefaçon sanctionnée par les articles L. 335-2 et suivants du Code de la propriété intellectuelle.

Diffusion Armand Colin, Paris — Dépôt légal : 2016 - nº 4, octobre-décembre 2016

Imprimé par l'Imprimerie Chirat, 42540 Saint-Just-la-Pendue, nº 201701.0091

Imprimé en France ISSN 0395-2649 